\title{
Explorando as transformações lineares no plano, através do software WINPLOT
}

\author{
Odileia da S. Rosa ${ }^{1}$, Ivy Goulart ${ }^{1}$, Leonardo Casanova ${ }^{1}$, Monique S. Lehmann ${ }^{1}$ \\ ${ }^{1}$ Universidade Severino Sombra, Discente do Programa de Pós-Graduação de \\ Mestrado Profissional em Educação Matemática \\ odileia.dasilvarosalgmail.com, ivy-goulart@hotmail.com, \\ leocasanovadglobo.com, moniquesequeiralyahoo.com.br,
}

\begin{abstract}
Resumo: As transformações lineares no plano são estudadas com maior afinco nas disciplinas de Álgebra Linear, e estas, muita das vezes não mostram as relações existentes da Álgebra Linear com a Geometria, fato este que faz com que o ensino de tal disciplina torne-se mais abstrata. A proposta deste artigo é explorar atividades com o uso do WINPLOT para mostrar as transformações lineares no plano e os tipos existentes, objetivando dar um suporte maior para a inserção das transformações lineares em outros espaços vetoriais e também estudar a Geometria das Transformações. O fato das transformações também serem uma função justifica ainda mais o uso do WINPLOT. As atividades sugeridas, que contemplam exemplos que facilitará o entendimento das definições que são apresentadas, normalmente, na disciplina de Álgebra Linear, fazendo um elo entre Álgebra e Geometria.
\end{abstract}

Palavras-Chave: álgebra linear, software Winplot, geometria.

\section{Introdução}

Nas disciplinas de Álgebra Linear enfatiza-se o conceito de transformações lineares, e, normalmente, vê-se um excessivo uso da álgebra sem relações com a Geometria, o que, acredita-se fazer com que a disciplina se torne mais abstrata.

Neste artigo abordaremos as transformações lineares no plano, ou seja, no $R^{2}$, utilizando o WINPLOT para auxiliar na visualização e no entendimento de tal conceito além do aluno poder manipular e aplicar o que aprendeu, fazendo o uso da Geometria das transformações. Um software educacional, como o WINPLOT, pode ser o elo de ligação entre os professores e os alunos e o seu o objetivo é ajudar a melhorar o processo ensino-aprendizagem de um conteúdo ou assunto educacional como mostra á Figura 1. Além disso, ele pode estimular um ambiente colaborativo entre professorestudante e estudante-estudante [Carvalho et al 2009].

Lima (1999) ressalta que o ensino de Matemática deva abranger três componentes fundamentais, a conceituação, a manipulação e a aplicação, sendo cada um deles necessários para o sucesso de um curso. Afirma ainda que deva haver uma dosagem de cada um desses três componentes, para que não ocorra como nas décadas de 60 e 70, que houve um excesso de conceituação não se detendo a detalhes usuais, fazendo com que os objetivos do ensino não fossem alcançados.

Acredita-se, então que a atividade proposta nesse artigo poderá auxiliar no ensino de Matemática, mais precisamente, no ensino de transformações lineares no 
plano, pois a mesma dará possibilidades ao aluno de conceituar, manipular e aplicar. É claro que não deve-se ficar somente nessa atividade, pois a mesma não contempla definições formais dos tipos das transformações lineares no plano, nas atividades trabalha-se com exemplos para que o aluno possa chegar a generalizações.

Usa-se o WINPLOT por ser, este, considerado um software livre para traçado de gráfico de funções com interface gráfica simples e com bastante facilidade de uso.

\section{Tecnologia e Educação}

Diversas pesquisas apontam que a utilização das tecnologias na educação tende a colaborar com o ensino/aprendizagem do indivíduo. Do ponto de vista didático acreditase que deva existir uma constante reflexão do professor, tendo em vista que existe uma mudança contínua no perfil do aluno e uma adequação do mesmo com a sociedade em que vive, que esta em constante evolução tecnológica.

Com isso torna-se necessária a inserção das tecnologias no ensino de Matemática a fim de dar possibilidade ao aluno de interagir com o meio em que vive. Apoiando-se no que diz Juanena (2005), devemos fixar nossa atenção aos estudos das interrelações entre o aspecto tecnológico, educativo e matemático.

Ele dá destaque a três características importantes do ponto de vista didático, quando o computador é utilizado com ferramenta em salas de aula. São elas:

1 - A atenção dos alunos volta-se ao sentido dos dados e a análise dos mesmos.

2 - Permite aos alunos conjecturar ordens com muito mais rapidez.

3 - Se converte em um poderoso instrumento de exploração e indagação.

Apoiando-se nessas três características destacadas por Juanena (2005), e nos três componentes principais para o ensino de Matemática, ressaltado por Lima (1999) procuramos desenvolver um projeto pedagógico utilizando o software WINPLOT, para mostrar os tipos de transformações lineares, possibilitando a visualização dos efeitos das mesmas sobre o plano. O que leva o aluno a se apropriar melhor do conceito de transformações lineares no plano.

\section{O WINPLOT}

O WINPLOT ${ }^{1}$ Escrito originalmente usando a linguagem $\mathrm{C}$, ele sofreu algumas mudanças na versão para o sistema Windows 98 e foi escrito na linguagem de programação $\mathrm{C}++$.

A escolha do WINPLOT se deu por ser este um programa desenvolvido para plotagem de funções, que é também uma transformação, por ser um programa gratuito e de simples manipulação. A ferramenta do programa que será utilizada na atividade proposta, o Mapeador, é uma ferramenta muito pouco utilizada. Com esta ferramenta pode-se trabalhar com transformações de $R^{2}$ em $R^{2}$.

\section{As transformações Lineares no plano e a Geometria.}

Segundo Fainguelernt (1999) a noção de matemática de movimento do plano está ligada ao conceito de grupo das transformações. O iniciador da teoria dos grupos, E. Galois, e mais tarde, o matemático alemão Felix Klein (1849-1925) partiram do estudo da estrutura do conjunto das transformações para ilustrar o conceito de grupo. Klein, em

\footnotetext{
${ }^{1}$ WINPLOT - é criação do professor Richard Parris, da Philips Exeter Academy por volta de 1985.O software pode ser acessado em http://math.exeter.edu/rparris/winplot.html
} 
1870, revolucionou o enfoque da Geometria ao afirmar que devemos entender seu contexto como o estudo das propriedades invariantes das figuras face às transformações de um grupo.

Para Klein (1872) o conceito de transformação desempenha um papel coordenador e simplificador no estudo da Geometria. O estudo da Geometria através das transformações possibilita uma abordagem intuitiva e informal, dando uma visão de forma e movimento.

As transformações lineares no plano, também podem ser chamadas de função e tem o domínio e o contradomínio sendo o $R^{2}$, o plano. Com isso as transformações lineares no plano, podem representar o movimento de uma figura geométrica no plano. Sendo este um dos objetivos das atividades propostas, a Geometria em movimento.

\section{$5 \quad$ A atividade - As transformações lineares no plano}

As atividades que serão propostas fazem uso do winplot para explorar os conceitos de transformações lineares no plano. Pretende-se explorar tal conceito em duas fases. Sendo elas:

\subsection{Fase 1 - Transformação linear no plano.}

Com o uso do WINPLOT será possível auxiliar a visualização da seguinte propriedade de transformações lineares no plano:

Toda transformação linear no plano é da forma:

$$
T(x, y)=(a x+b y, c x+d y),
$$

Um vetor do plano sempre pode ser transformado em outro vetor do plano, quando se efetua o produto matricial:

$$
\left(\begin{array}{ll}
a & \mathrm{~b} \\
c & \mathrm{~d}
\end{array}\right)\left(\begin{array}{l}
\mathrm{x} \\
\mathrm{y}
\end{array}\right)=\left(\begin{array}{l}
a x+b y \\
c x+d y
\end{array}\right) .
$$

Para dar possibilidades ao aluno de visualizar a propriedade acima será necessário variar os coeficientes $\mathrm{a}, \mathrm{b}, \mathrm{c}, \mathrm{d}$, da matriz, pois variando os mesmos continuase com matrizes $2 \times 2$, porém, as mesmas serão diferentes.

Para isso utiliza-se a ferramenta Mapeador, muito pouco explorada. Pode-se notar, durante a utilização dessa ferramenta, que duas telas são geradas: o Domínio e o Contradomínio da transformação linear no plano, $o R^{2}$. 


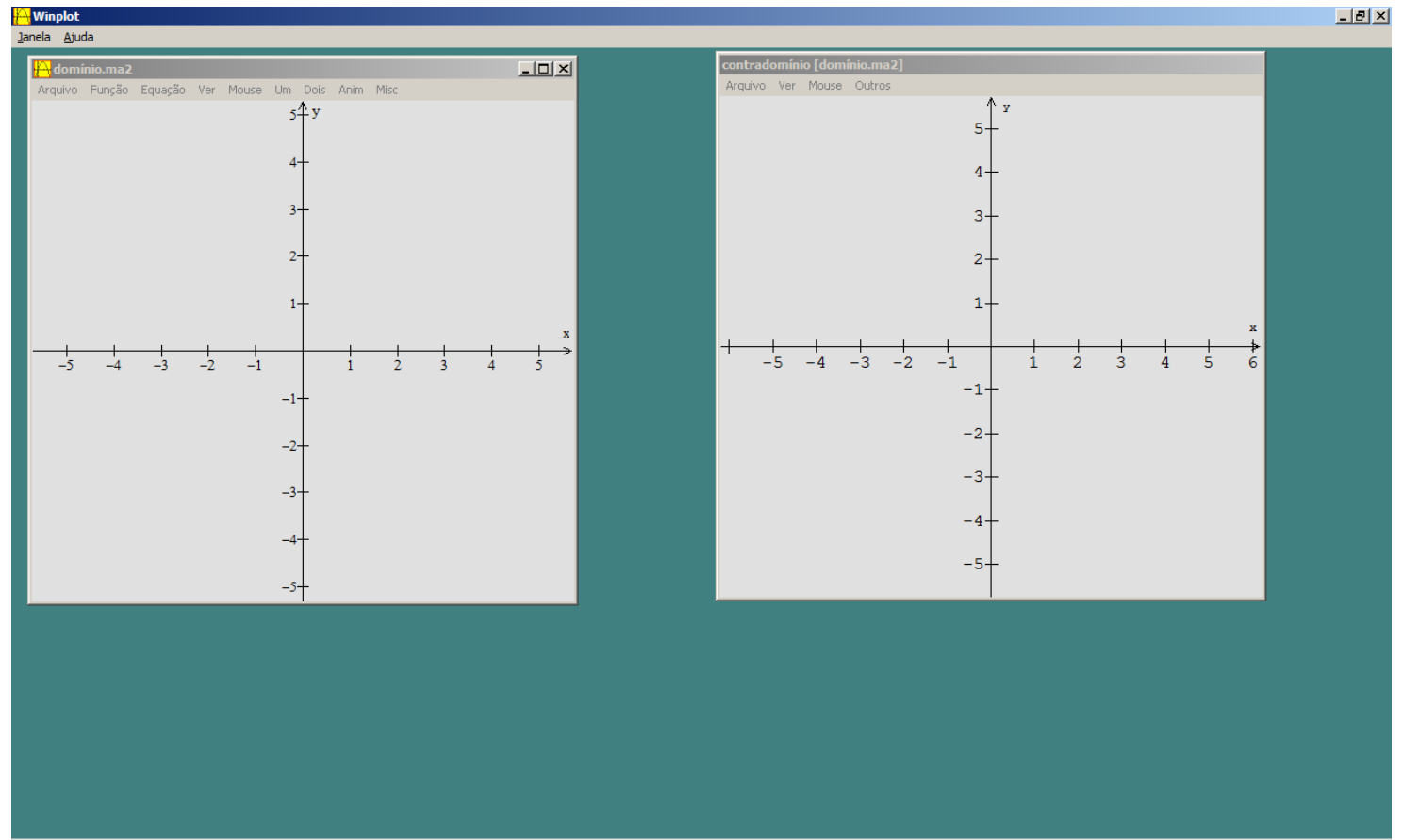

Figura 1: Tela do Winplot com a ferramenta Mapeador ativada.

Considerando os pontos: $\mathrm{A}=(0,0), \mathrm{B}=(4,0), \mathrm{C}=(4,4)$ e $\mathrm{D}=(0,4)$ e traçando-se os segmentos: $\overline{A B}, \overline{B C}, \overline{C D}$ e $\overline{D A}$, tem-se um quadrado de lado 4, conforme segue:

À medida que os segmentos são traçados no domínio são gerados os mesmos no contradomínio, conforme a figura 2.
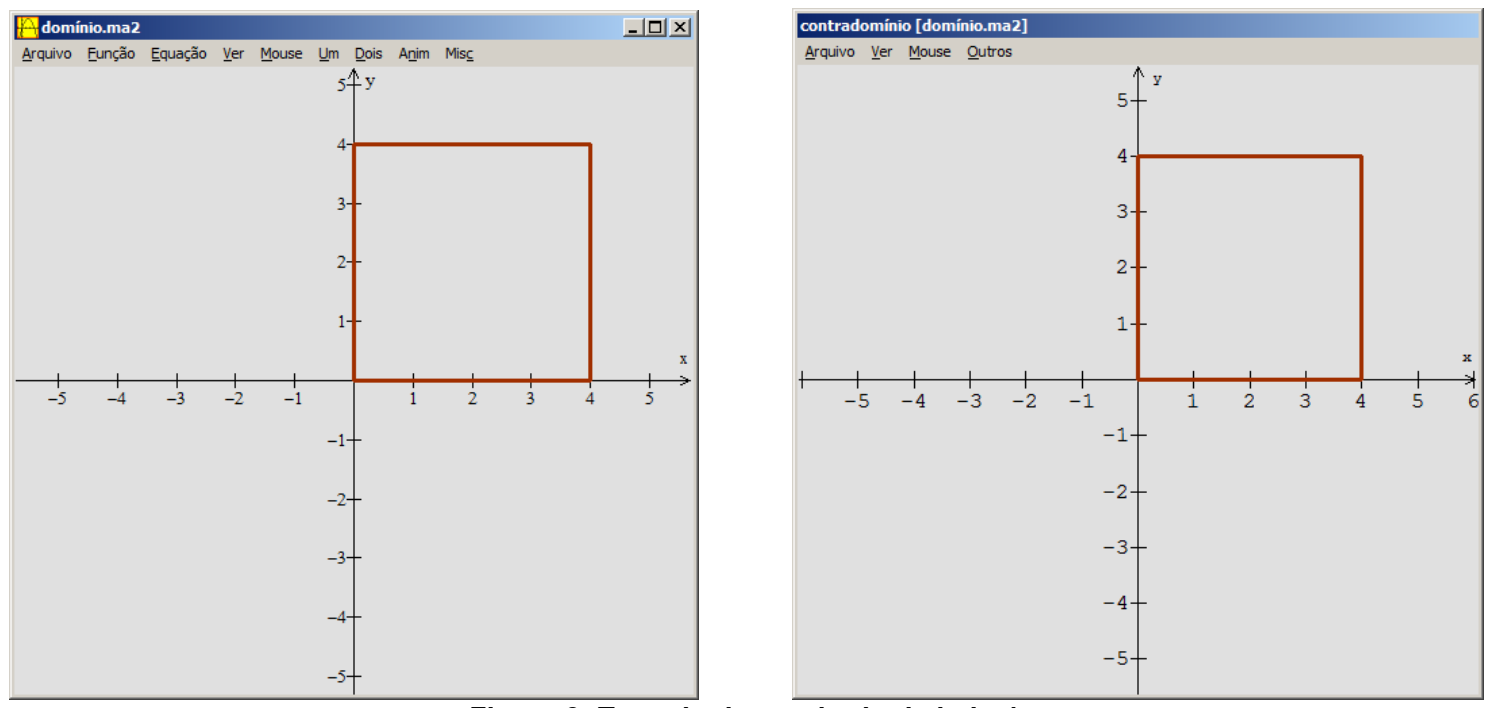

Figura 2: Traçado do quadrado de lado 4.

Para visualizar o que foi proposto. Insere-se a seguinte função:

$T(x, y)=(a x+b y, c x+d y)$, que é a função de toda transformação linear no plano.

Verifica-se que ao serem variados os coeficientes a, b, c e d, que todos os pontos continuam pertencendo ao plano, podendo não conservar a forma do quadrado. $\mathrm{O}$ aluno poderá explorar a variação desses valores e chegar a conjecturas, confirmando assim a propriedade acima. 
Na figura 3, optou-se por variar os coeficientes a, b, c e d, respectivamente, para $4,2,1$ e 4 .
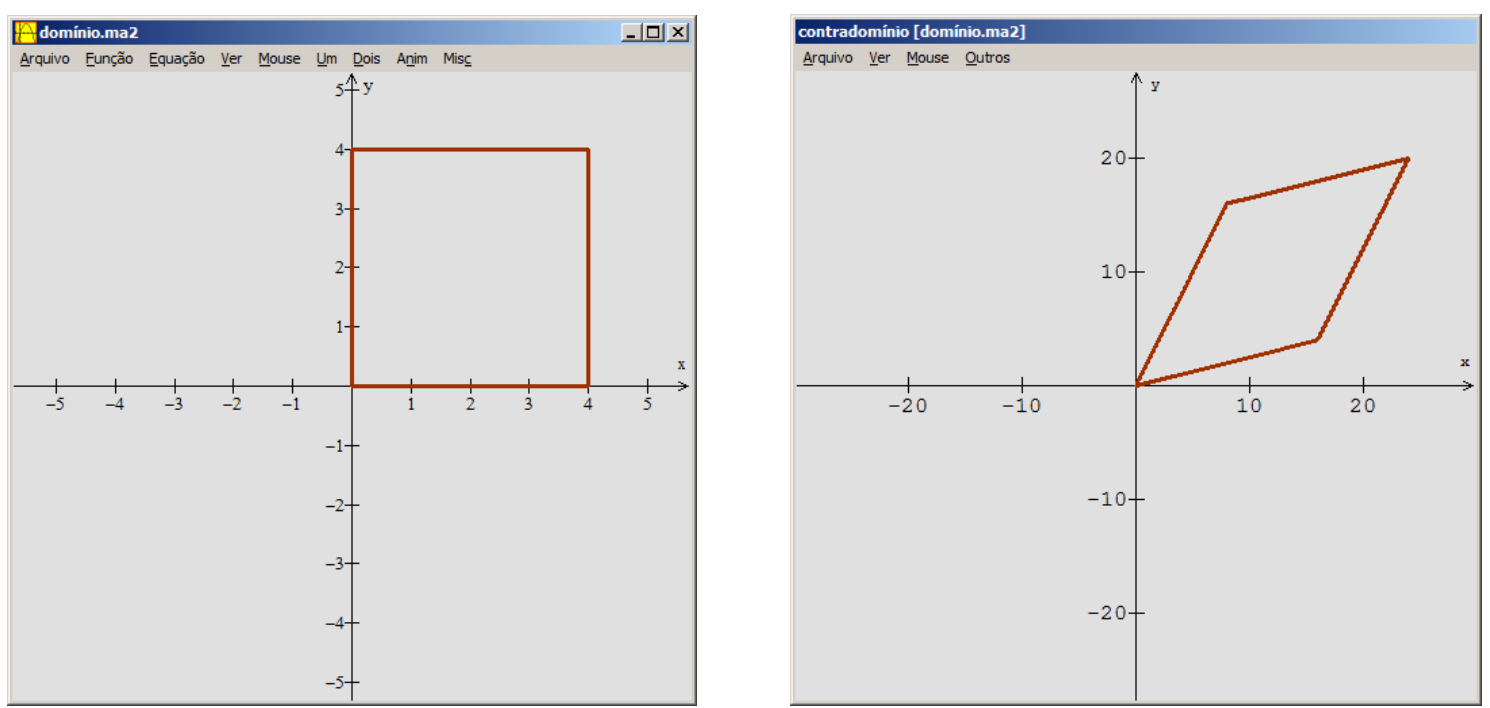

Figura 3: Gráfico de $T(x, y)=(4 x+2 y, x+4 y)$.

\subsection{Fase 2: Tipos de transformações lineares}

Após a exploração da atividade da fase 1, algumas regularidades poderão aparecer. Como por exemplo, o quadrado se transformar no ponto $(0,0)$, na origem do plano, nesse caso, os coeficientes a, b, c e d, serão todos 0 (zero).

Nesse momento, poderá haver a intervenção do professor, afim de mediar as variações dos coeficientes, para que os alunos possam chegar aos tipos de transformações lineares no plano, conhecidas. Pretende-se, então, nesta segunda fase, a partir da atividade da fase 1 , mostrar cada um dos tipos de transformações lineares no plano através de exemplos, levando o aluno a visualizar o que acontece. O objetivo, primordial é que essa atividade seja realizada, antes, de definir os tipos de transformações lineares no plano. Acredita-se que com esse argumento didático o aluno é capaz de explorar melhor os conhecimentos ficando mais fácil de defini-los posteriormente.

\subsubsection{Atribuindo o valor 0 (zero)}

Atribuindo-se o valor 0 (zero) para todos os coeficientes, teremos a Transformação Nula, conforme figura 4.

O aluno poderá visualizar o que acontece. Chegando que: A transformação linear nula, transforma todos os pontos do domínio no ponto $(0,0)$, o que o aluno poderá verificar. 

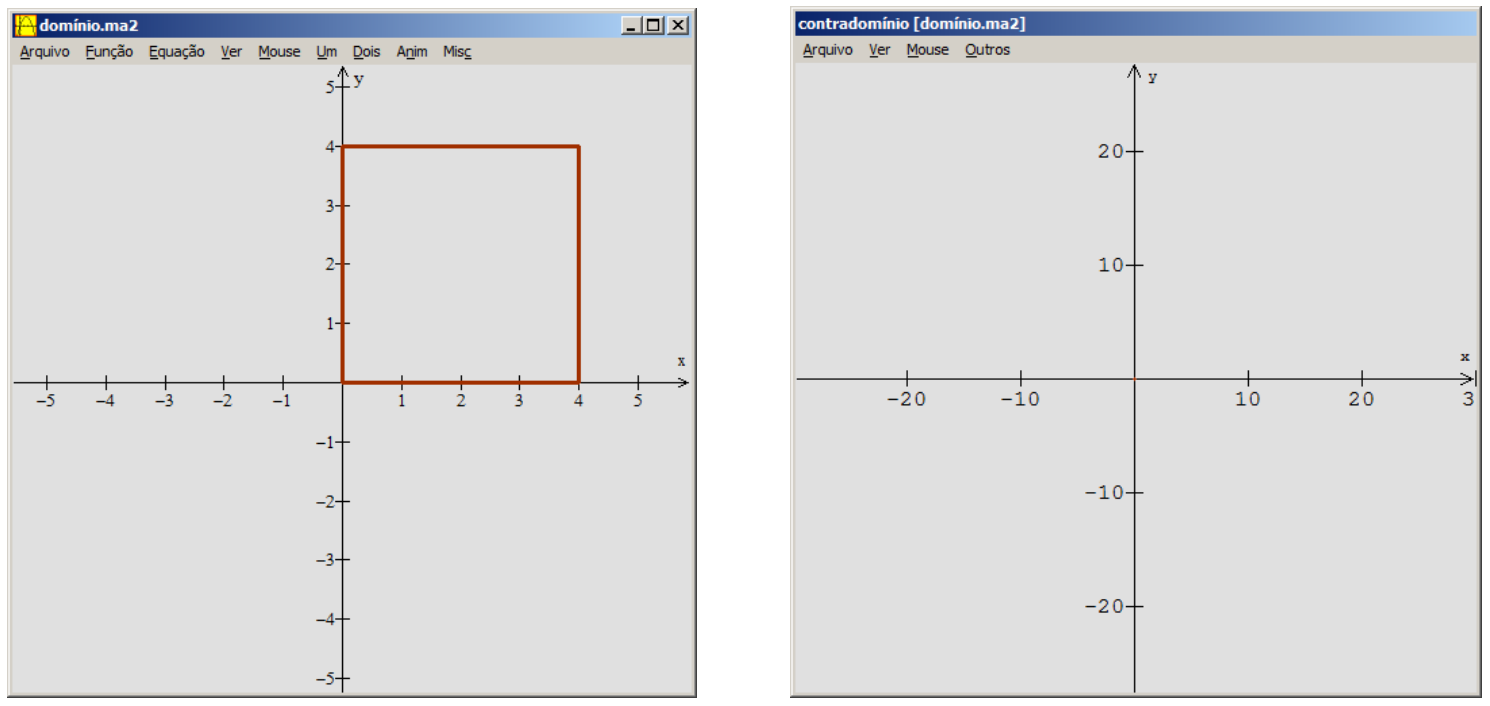

Figura 4: Transformação nula - $T(x, y)=(0 x+0 y, 0 x+0 y)=(0,0)$

\subsubsection{Atribuindo o valor 1 (um)}

Atribuindo-se o valor 1 (um) para os coeficientes a e d, e para os coeficientes b e c 0 (zero), teremos a Transformação Identidade, conforme figura 5.

A Transformação identidade transforma todos os pontos do plano nele mesmo.
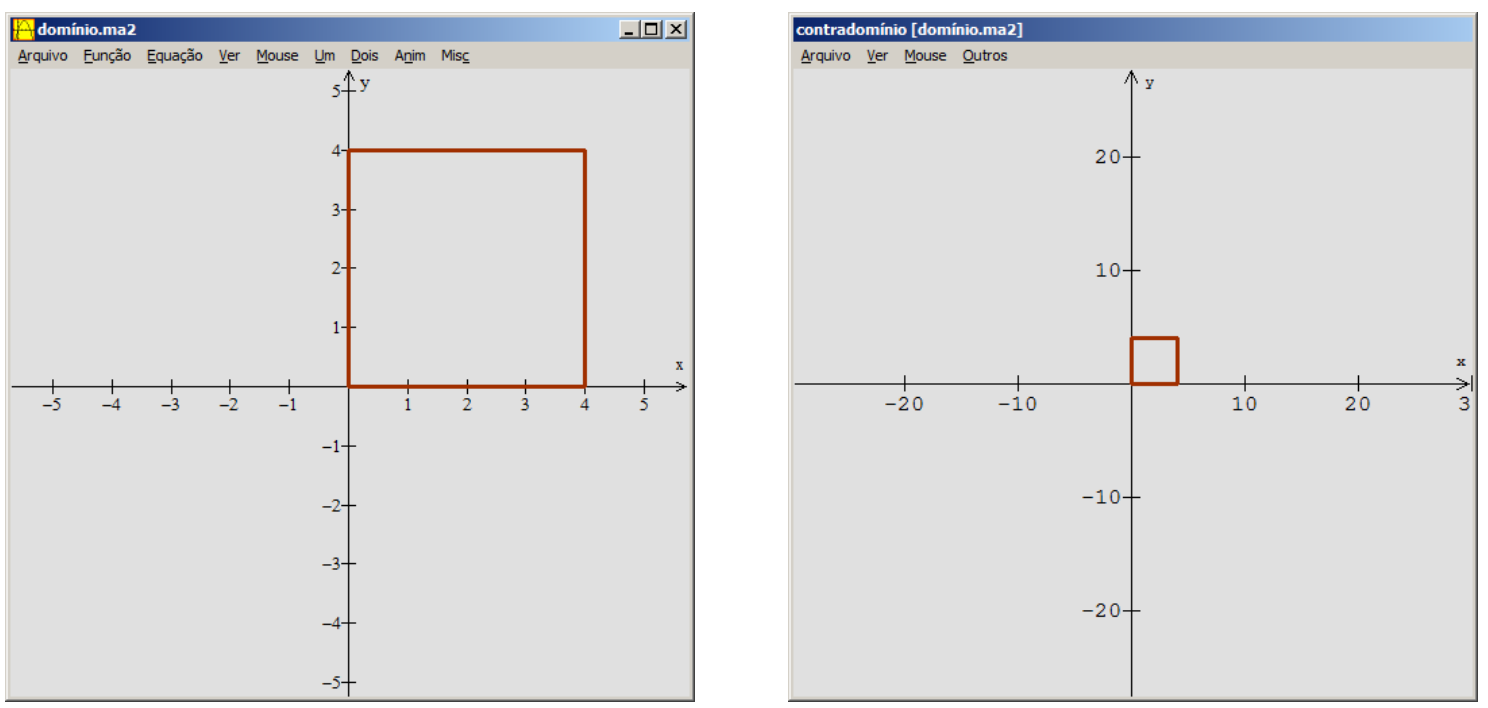

Figura 5: Transformação identidade - $T(x, y)=(1 x+0 y, 0 x+1 y)=(x, y)$

Da forma com que a imagem se apresentou pode-se explorar para que serve a utilização de escala, mostrando que os quadrados são congruentes.

\subsubsection{Atribuindo o valor 5 (cinco)}

Atribuindo-se o valor 5 (cinco) para os coeficientes a e d e para os coeficientes b e c 0 (zero), teremos uma Homotetia de razão 5 (cinco), conforme figura 6. 

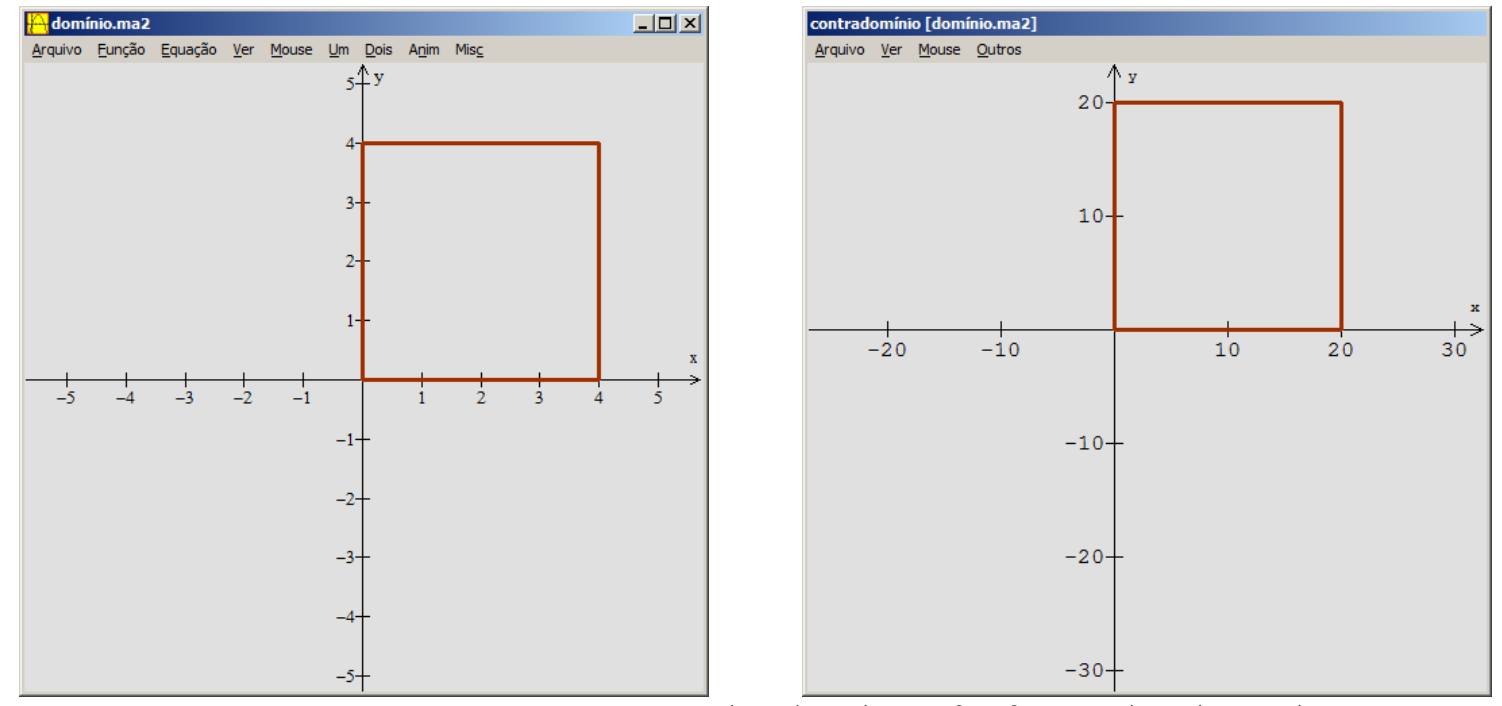

Figura 6: Homotetia de razão $5-T(x, y)=(5 x+0 y, 0 x+5 y)=(5 x, 5 y)$

5.2.4 - Atribuindo-se para os coeficientes a e d, -1, e para os coeficientes b e c, 0 (zero)

Atribuindo-se para os coeficientes a e d, -1, e para os coeficientes b e c, 0 (zero), teremos uma Simetria Central, conforme figura 7.
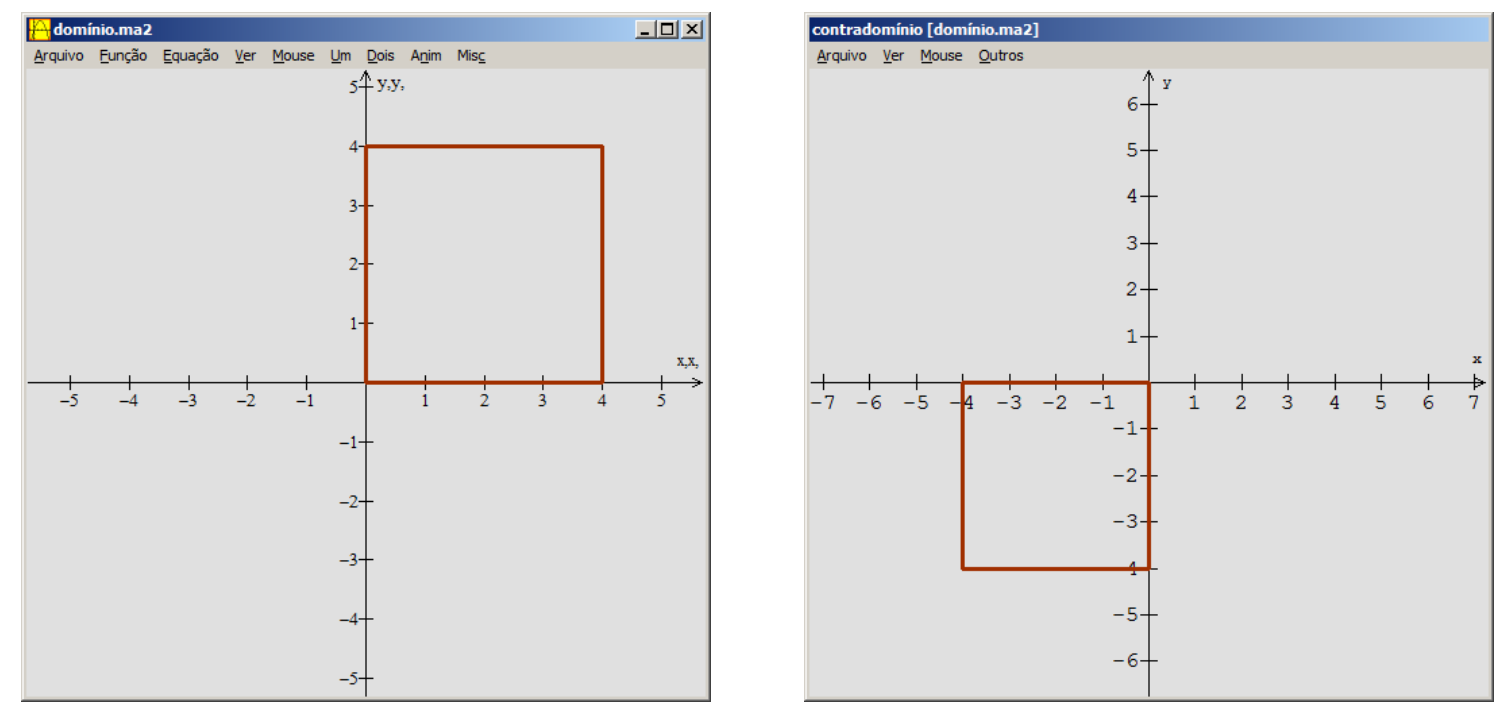

Figura 7: Simetria Central $-T(x, y)=(-x+0 y, 0 x+-y)=(-x,-y)$

\section{b,c e d}

5.2.5 Atribuindo-se 1 (um) para o coeficiente a e 0 (zero) para os coeficientes

Atribuindo-se 1 (um) para o coeficiente a e 0 (zero) para os coeficientes b,c e d teremos uma Projeção em OX, conforme figura 8. 

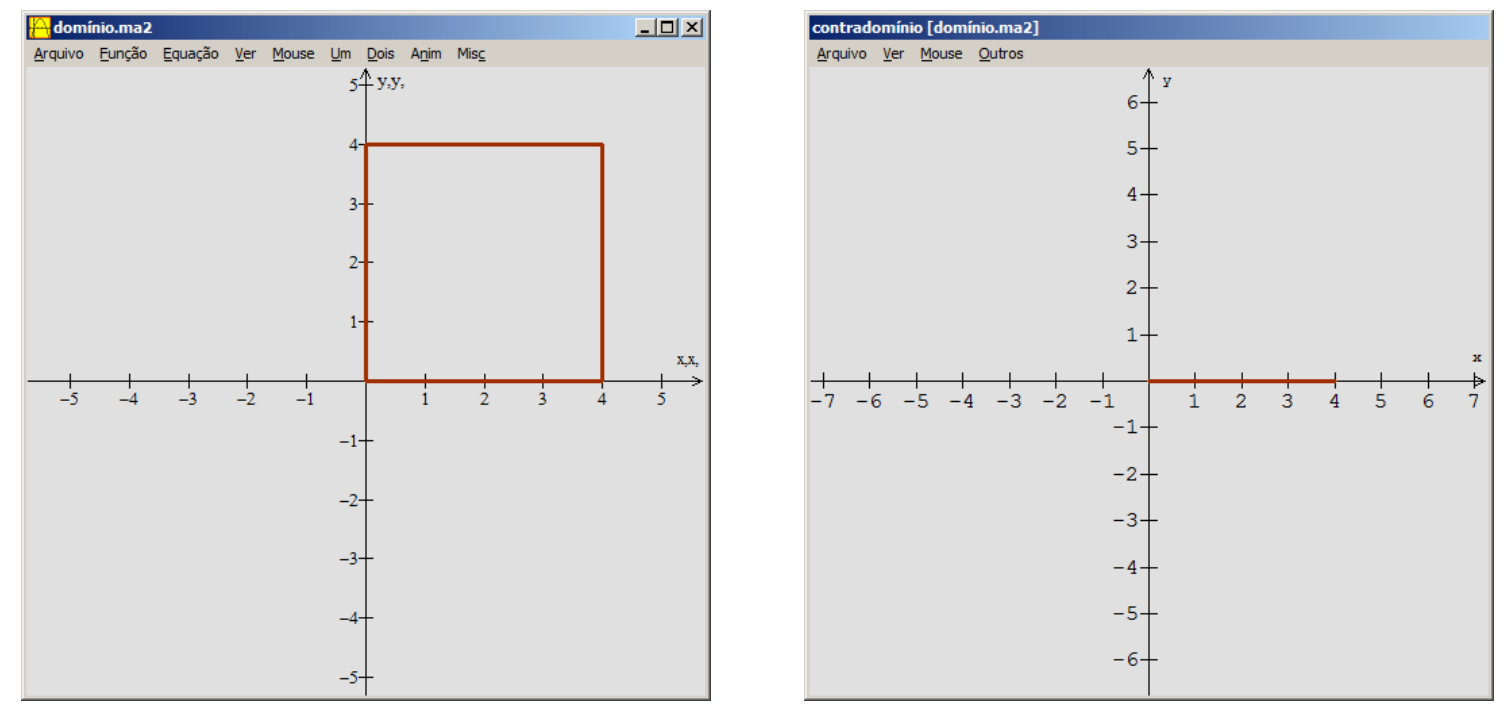

Figura 8: Projeção em OX $-T(x, y)=(x+0 y, 0 x+0 y)=(x, 0)$

5.2.6 - Atribuindo-se 1 (um) para o coeficiente a, 0 (zero) para os coeficientes b e c, e 2 (dois) para o coeficiente d

Atribuindo-se 1 (um) para o coeficiente a, 0 (zero) para os coeficientes b e c, e 2 (dois) para o coeficiente d teremos um Alongamento, conforme figura 9.
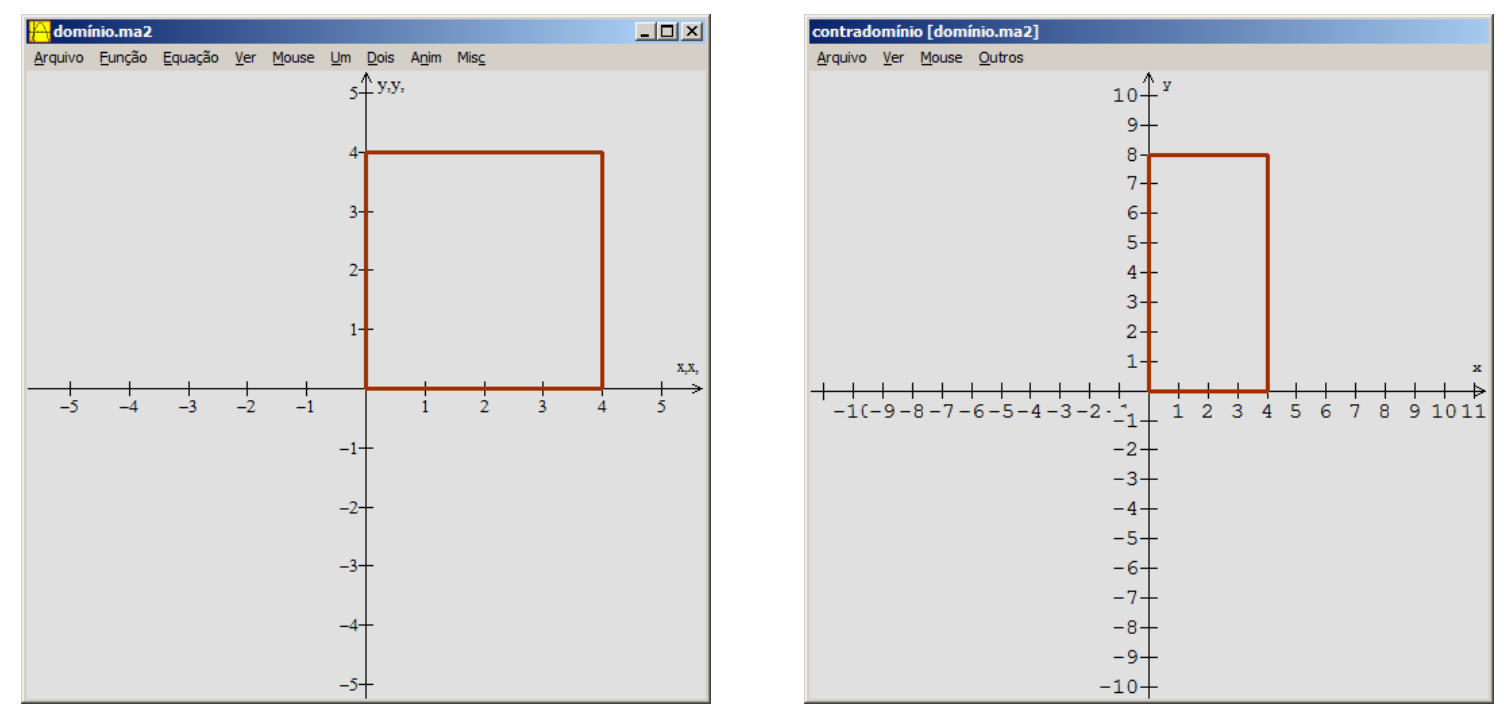

Figura 9: Alongamento $-T(x, y)=(x+0 y, 0 x+2 y)=(x, 2 y)$

5.2.7 - Atribuindo-se $\cos (o)$ para os coeficientes a e d, - $\operatorname{sen}(o)$ para o coeficiente b e $\operatorname{sen}(o)$ para o coeficiente c, sendo o, o ângulo

Atribuindo-se $\cos (o)$ para os coeficientes a e d, - $\operatorname{sen}(o)$ para o coeficiente b e $\operatorname{sen}(o)$ para o coeficiente c teremos uma Rotação, sendo o, o ângulo de rotação, conforme figura 10.

Observe que a circunferência foi divida em 12 partes, logo a rotação foi de $240^{\circ}$, 
porem $0=4,2$.
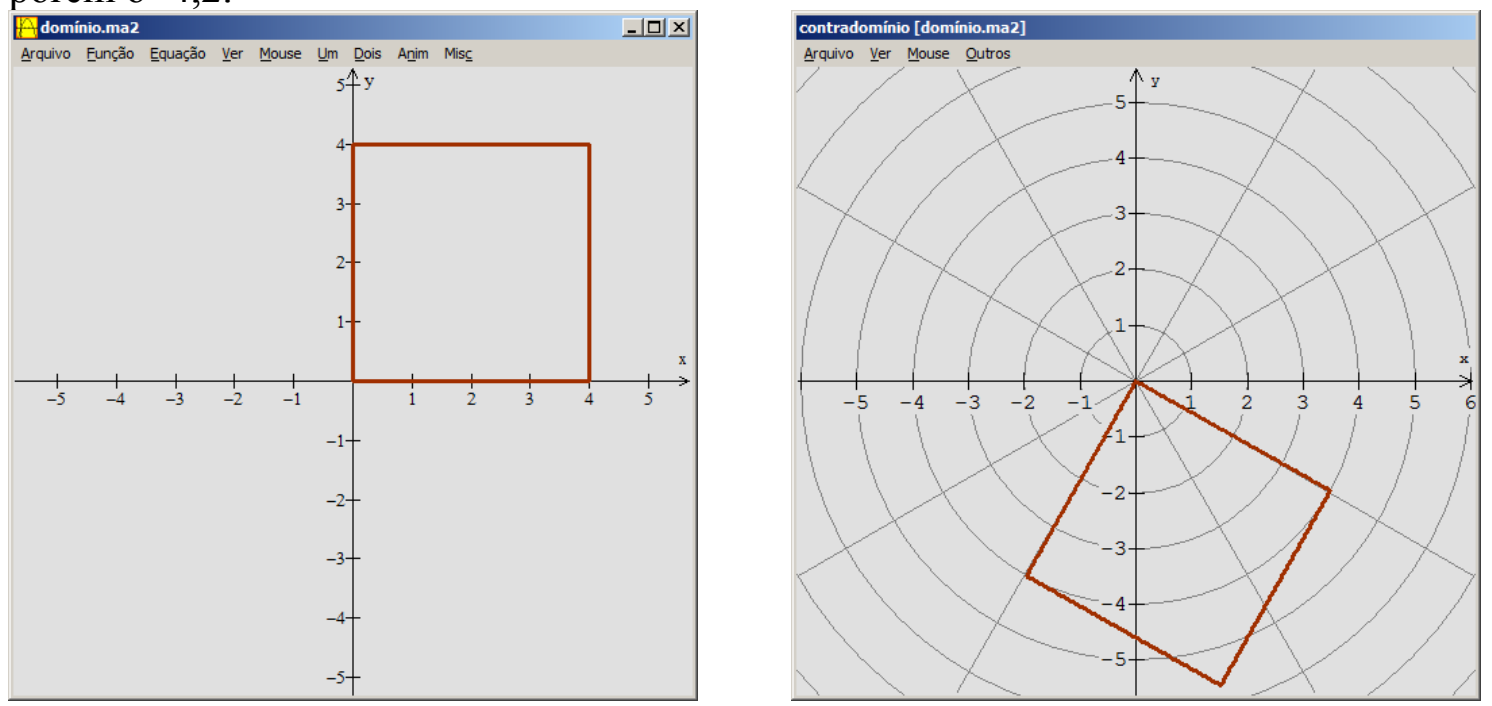

Figura 10: Rotação $-T(x, y)=\left(x \cos \left(240^{\circ}\right)-y \operatorname{sen}\left(240^{\circ}\right), x \operatorname{sen}\left(240^{\circ}\right)+y \cos \left(240^{\circ}\right)\right)$.

5.2.8 - Atribuindo-se 1 para os coeficientes a e d, 0 para o coeficiente c e 4 para o coeficiente $b$

Atribuindo-se 1 para os coeficientes a e d, 0 para o coeficiente c e 4 para o coeficiente $\mathrm{b}$ teremos um Cisalhamento paralelo a $\mathbf{O X}$, conforme figura 11 .
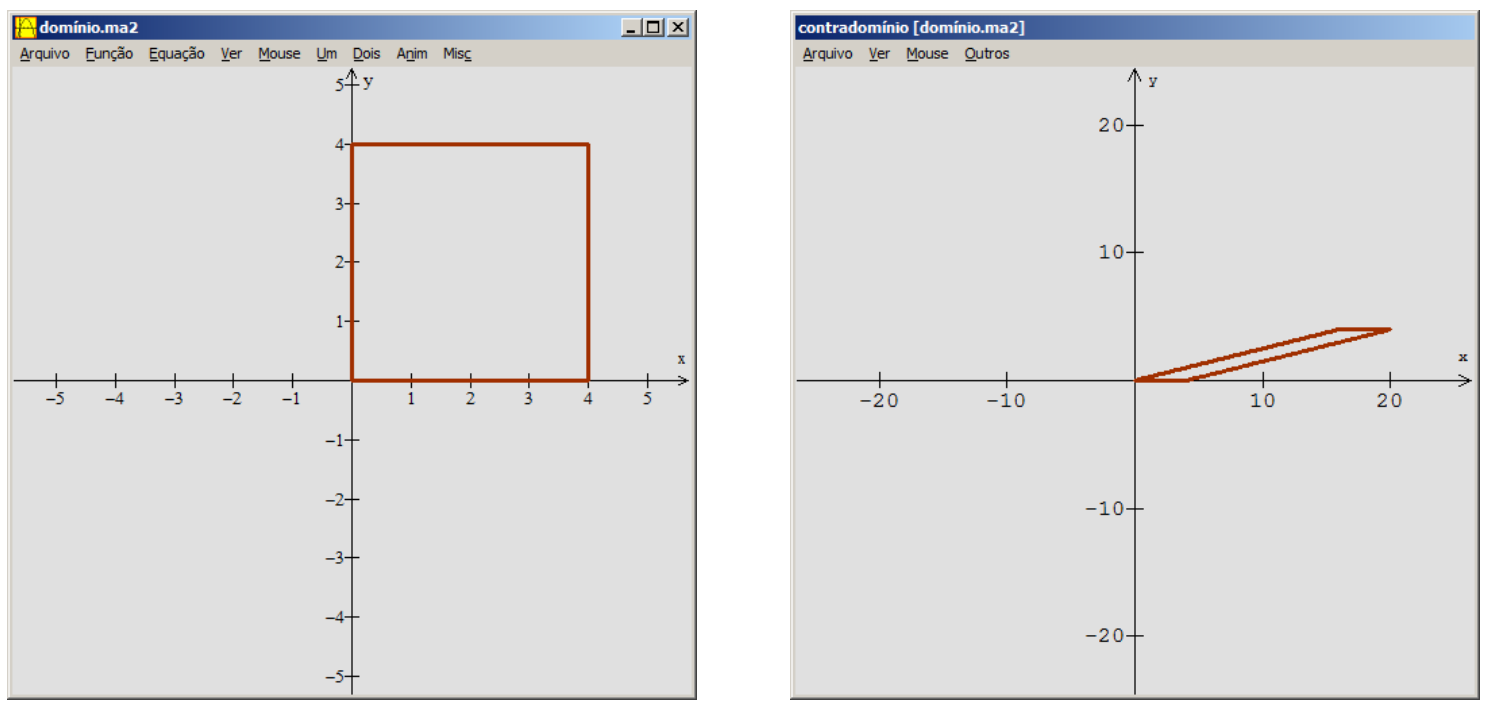

Figura 11: Cisalhamento paralelo a OX $-T(x, y)=(x+4 y, 0 x+y)=(x+4 y, y)$.

5.2.9 - Atribuindo-se 1 para os coeficientes a e d, 0 para o coeficiente b e 4 para o coeficiente c

Atribuindo-se 1 para os coeficientes a e d, 0 para o coeficiente b e 4 para o coeficiente $\mathrm{c}$ teremos um Cisalhamento paralelo a $\mathbf{O Y}$, conforme figura 12. 

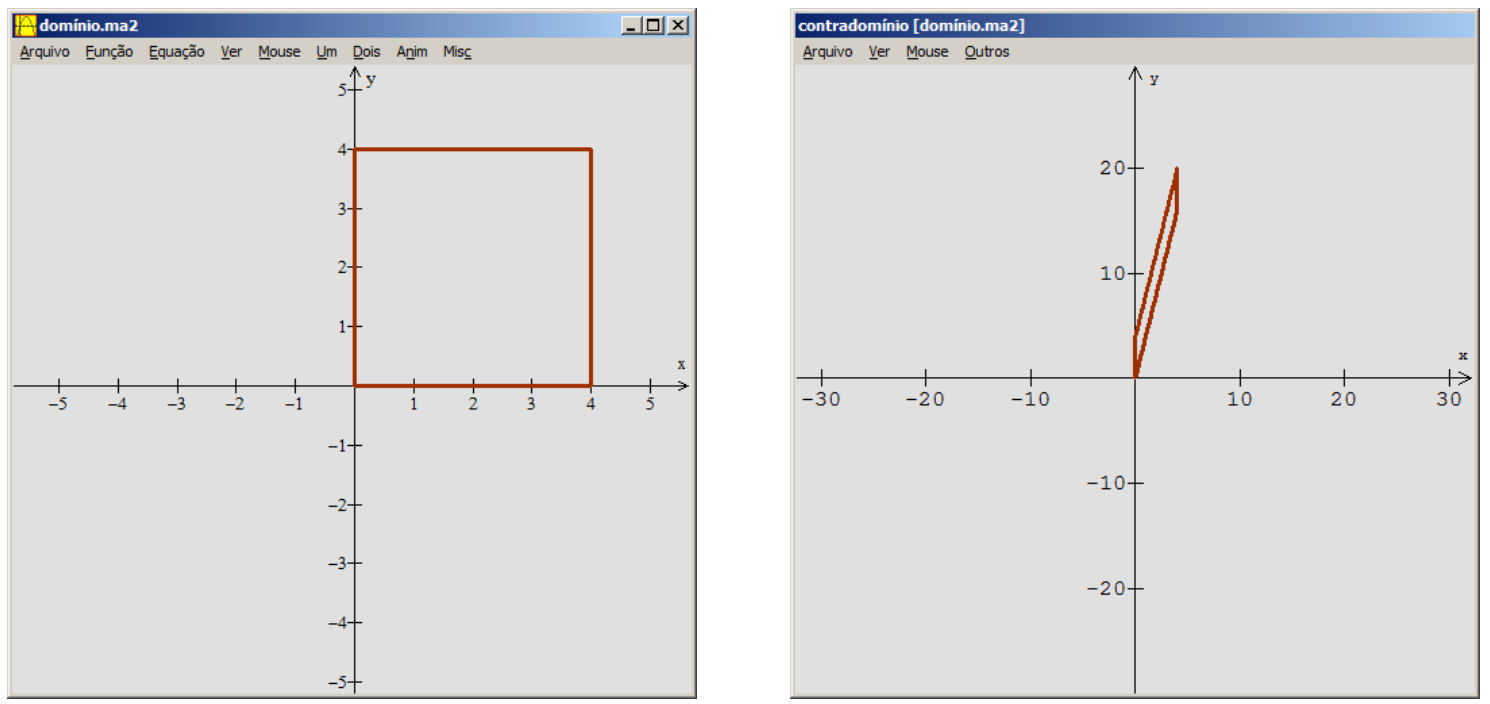

Figura 12: Cisalhamento paralelo a oY $-T(x, y)=(x+0 y, 4 x+y)=(x, 4 x+y)$.

Nesse caso podem-se explorar as diferenças existentes entre o cisalhamento paralelo a OX e OU.

Os tipos de transformações lineares são mostrados através de exemplos construídos pelos próprios alunos, fazendo com que este possa interagir. A visualização é de suma importância nestas atividades.

\section{Considerações Finais}

Acredita-se que com as atividades que foram propostas, os alunos poderão abstrair melhor o conceito de transformações lineares no plano e, posteriormente, em outros espaços vetoriais.

Ao ser utilizado o WINPLOT o aluno poderá visualizar, manipular e aplicar, entendendo melhor o conceito de transformações lineares no plano.

A ferramenta Mapeador possibilita ao aluno visualizar o passo a passo da transformação dando movimento a cada variação feita. A figura vai movimentando-se à medida que vão mudando os coeficientes, não apenas mostrando o resultado final.

O WINPLOT dá a capacidade do aluno, visualizar a geometria em movimento, ao serem modificados os coeficientes, e em parelelo verificar que o movimento ocorre quando a função muda.

Além das abordagens feitas sobre as transformações lineares no plano podem-se inserir ao longo das construções vários conceitos que vão surgindo. Como por exemplo: Os conceitos de domínio e imagem que estão em todas as construções muito presente.

Apesar da ferramenta Mapeador do WINPLOT ser muito pouco utilizada, verificou-se neste artigo que com a mesma é possível, transformar um conceito abstrato, como o das transformações lineares, em um estudo prazeroso e eficaz.

\section{Referências Bibliográficas}

Carvalho, J. P. da. Álgebra Linear - Introdução. Rio de Janeiro: LTC, 1979.

Dienes, Z.P. \& Golding, E.W. A Geometria pelas Transformações. São Paulo: Herder, 1972. 
Fainguelernt, E. K.. Educação Matemática - Representação e Construção em Geometria. Porto Alegre: Artmed, 1999.

Fainguelernt, E. K. \& Bordinhão, N. de C.. Álgebra Linear / Geometria Analítica. Rio de Janeiro: Art Bureau Edições de arte, 2000.

Howard, A.. Álgebra Linear com Aplicações. Porto Alegre: Bookman, 2001.

Juanena, J. M. S.. Estudio de una estrategia didáctica basada en las nuevas tecnologías para la enseñanza de la Geometria. Madrid, 2005. Tese - Faculdade de Educação. Universidad Complutense de Madrid.

Lima, E. L. Conceituação, manipulação e aplicação: os três componentes do ensino de Matemática. Revista do Professor de Matemática. São Paulo, n. 41, 1999, p.1-6.

Oliveira, A. M. de \& Silva, A.. Biblioteca da Matemática Moderna. São Paulo: LISA, 1968. v.3. 